\title{
Galectins participate in virus infection, friend or foe?
}

\author{
Wen-Hung Wang ${ }^{1}$, Max R Chang Ishcol ${ }^{2}$, Chih-Yen Lin $^{3}$ and Sheng-Fan Wang ${ }^{3 *}$ \\ ${ }^{1}$ Division of Internal Medicine, Kaohsiung Municipal Hsiao-Kang Hospital, Kaohsiung Medical University, Taiwan \\ ${ }^{2}$ Program in Tropical Medicine, College of Medicine, Kaohsiung Medical University, Taiwan \\ ${ }^{3}$ Department of Medical Laboratory Science and Biotechnology, Kaohsiung Medical University, Taiwan
}

Galectins, previously called as S-type lectins, have high affinity to $\beta$-galactose-containing glycoconjugates. Galectins contain carbohydrate-recognition domains (CRDs) that share structural homology. Galectins are known to widely express in all organisms and participate in regulation of various biological, physiological and immunological functions. In recent years, galectins have been reported to play certain roles in viral infections. Some viruses take advantage of galectins to enhance their propagation. However, some viral infections are reported to be ameliorated by galectins. Some galectins are known to address dual roles (promotion or inhibition) mainly determined on their intracellular or extracellular functions. Here, we briefly address the roles of galectins in virus infection.

Galectins were firstly found in vertebrates in 1976, the first found of galectins is named as Galectin-1. After that, a number of galectins have been identified. Currently, there are 15 galectins found in mammals and 12 of them were identified in humans (Figure 1). The primary structure of galectins shares the carbohydrate recognition domains (CRDs) that interact to $\beta$-galactosides and some of them connect to a tandem repeat domain. Galectins are classified into three main groups including prototype, chimera and tandem repeat type (Figure 1). Presently, limited information is available regarding the role of galectins in virus infection, replication and dissemination. Several reports indicate that galectins regulate virus infections through their intracellular and extracellular interactions with factors that reside in the nucleus and cytoplasm and glycans on cell surface, respectively. Galectin-1 has been reported to act as a host soluble factor to promote HIV-1 infection via a mechanism that interacts with gp120 envelope protein of HIV-1 as well as $\mathrm{CD} 4$ receptors on the cell surface, contributing to enhancement of
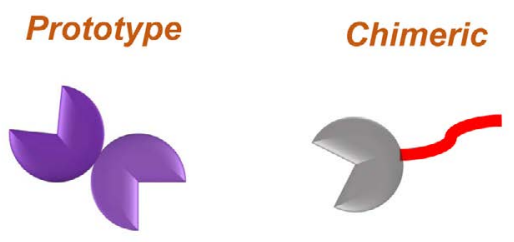

Tandem repeat

\begin{tabular}{|c|c|c|}
\hline Galectin-1 & Galectin-3 & Galectin-4 \\
\hline Galectin-2 & & Galectin-8 \\
\hline Galectin-7 & & Galectin-9 \\
\hline Galectin-10 & & Galectin-12 \\
\hline
\end{tabular}

Galectin-14

Figure 1. Different types of galectins in humans Human galectins have been classified into three groups according to their structure: prototypical, chimeric, and tandem repeat. virions attaching to CD4. Similar phenomenon was found in monocytes and macrophages receiving HIV-1 infection in presence of Galectin-1. In addition, Galectin-1 is reported to bind to influenza virus and ameliorates influenza induced pathogenesis [1], also Galectin-1 was found to facilitate suppression of Epstein-Barr virus (EBV)-specific T-cell replication [2]. Galectin-1 is also reported to inhibit cell fusion by envelope glycoproteins of Nipah virus and triggered the secretion of proinflammatory cytokines [3] and exerts inhibitory effects against dengue virus serotype 1(DV-1) infection [4]. Further, herpes simplex virus(HSV) infection is known to induce Galectin-1 expression and secretion, leading to cause of apoptosis of activated $\mathrm{T}$ cells [5]. These observations are mainly relied on the extracellular functions of Galectin-1 to virus infection using in vitro models.

Regarding to Galectin-3, it has a unique chimeric structure composed by one CRD linking and a tandem repeat domain. An earlier report indicates that herpes simplex virus type $1(\mathrm{HSV}-1)$ infection rose Galectin-3 secretion and contributed to pro-inflammatory immune response against HSV-1 infection [6]. The other report indicates that Aloe-emodin treatment up-regulated Galectin-3 to against Influenza A virus infection, since Galectin-3 presented cytokine-like regulatory function to activate JAK/STAT pathway and further to augment expression of antiviral genes, such as IFN- $\beta$, IFN- $\alpha$ and PKR [7]. More recently, Galectin-3 was reported to express and correlate with HIV1 expression in latent infected cells through interacting with Tat and activating NF- $\kappa B$ pathway. In addition, the endogenous function of Galectin-3 in virus infection has been recently addressed. A report indicates that endogenous Galectin-3 was up-regulated in HIV-1 infected CD4 T cells and further promoted HIV-1 budding through stabilizing Alix and p6 $^{\text {Gag }}$ interaction [8]. Recently, another study indicated that endogenous gaectin-3 triggered NLRP3 inflammasome activation to increase severity of $\mathrm{H} 5 \mathrm{~N} 1$-avian influenza virus-induced pulmonary inflammation [9].

Regarding the regulatory capabilities of Galectin-9 in virus infection, several researches indicated that Galectin-9 displayed inhibitory effects on virus replication and propagation. Previous reports indicate that Galectin-9 interacted with T cell immunoglobulin and mucin protein-3 (Tim-3) which induced apoptosis of virus infected T cells such as HTLV-1 [10]. Galectin-9/Tim-3 interaction also known to constrain

${ }^{\star}$ Correspondence to: Sheng-Fan Wang, Department of Medical Laboratory Science and Biotechnology, Kaohsiung Medical University, Kaohsiung 80708 Taiwan, Tel: +886-7-3121101\#2558; Fax: +886-7-322-2783, E-mail: wasf1234@ kmu.edu.tw

Received: March 10, 2019; Accepted: March 17, 2019; Published: March 20, 2019 
CD8 T cell immunity to HSV infection and ameliorates HSV-induced inflammation $[11,12]$. Similar results were also found in influenza A virus and respiratory syncytial virus when Galectin- 9 bound to virus infected $\mathrm{T}$ cells $[13,14]$. Furthermore, Tim-3/Galectin-9 pathway upregulation resulted in exhaustion of $\mathrm{T}$ cells in chronic hepatitis $\mathrm{B}$ virus infection [15]. In addition, the increase of Galectin-9 expression in sera or plasma was correlated with influenza A virus, HIV-1 and dengue virus infections in the early phase, suggesting Galectin- 9 as a biomarker to monitor some virus infection and disease severity [16-18].

Here, we briefly introduced the current research status of galectins in virus infection. Although significant positive or negative viral regulation by galectins were reported using recombinant galectin pretreated in in vitro assays, we need to consider the possibility of these galectins' regulation in in vivo models, because the concentrations of most galectins are in nanomolar (nM) range in human body. We suggest that endogenous function of galectins is worthy to study, the mechanism may be through protein-protein interaction inside the cells.

\section{References}

1. Yang ML, Chen YH, Wang SW, Huang YJ, Leu CH, et al. (2011) Galectin-1 binds to influenza virus and ameliorates influenza virus pathogenesis. J Virol 85: 10010-10020. [Crossref]

2. Gandhi MK, Moll G, Smith C, Dua U, Lambley E, et al. (2007) Galectin-1 mediated suppression of Epstein-Barr virus specific T-cell immunity in classic Hodgkin lymphoma. Blood 110: 1326-1329. [Crossref]

3. Levroney EL, Aguilar HC, Fulcher JA, Kohatsu L, Pace KE, et al. (2005) Novel innate immune functions for galectin-1: galectin-1 inhibits cell fusion by Nipah virus envelope glycoproteins and augments dendritic cell secretion of proinflammatory cytokines. $J$ Immunol 175: 413-420. [Crossref]

4. Toledo KA, Fermino ML, Andrade Cdel C, Riul TB, Alves RT, et al. (2014) Galectin-1 exerts inhibitory effects during DENV-1 infection. PLoS One 9: e112474. [Crossref]

5. Gonzalez MI, Rubinstein N, Ilarregui JM, Toscano MA, Sanjuan NA, et al. (2005) Regulated expression of galectin-1 after in vitro productive infection with herpes simplex virus type 1: implications for T cell apoptosis. Int J Immunopathol Pharmacol 18: 615-623. [Crossref]

6. King RD, Lubinski JM, Friedman HM (2009) Herpes simplex virus type 1 infection increases the carbohydrate binding activity and the secretion of cellular galectin-3. Arch Virol 154: 609-618. [Crossref]
7. Li SW, Yang TC, Lai CC, Huang SH, Liao JM, et al. (2014) Antiviral activity of aloeemodin against influenza A virus via galectin-3 up-regulation. Eur J Pharmacol 738 : 125-132. [Crossref]

8. Wang SF, Tsao CH, Lin YT, Hsu DK, Chiang ML, et al. (2014) Galectin-3 promotes HIV-1 budding via association with Alix and Gag p6. Glycobiology 24: 1022-1035. [Crossref]

9. Chen YJ, Wang SF, Weng IC, Hong MH, Lo TH, et al. (2018) Galectin-3 Enhances Avian H5N1 Influenza A Virus-Induced Pulmonary Inflammation by Promoting NLRP3 Inflammasome Activation. Am J Pathol 188: 1031-1042. [Crossref]

10. Okudaira T, Hirashima M, Ishikawa C, Makishi S, Tomita M, et al. (2007) A modified version of galectin-9 suppresses cell growth and induces apoptosis of human T-cell leukemia virus type I-infected T-cell lines. Int J Cancer 120: 2251-2261. [Crossref]

11. Sehrawat S, Reddy PB, Rajasagi N, Suryawanshi A, Hirashima M, et al. (2010) Galectin-9/TIM-3 interaction regulates virus-specific primary and memory CD8 T cell response. PLoS Pathog 6: e1000882. [Crossref]

12. Shim JA, Park S, Lee ES, Niki T, Hirashima M, et al. (2012) Galectin-9 ameliorates herpes simplex virus-induced inflammation through apoptosis. Immunobiology 217: 657-666. [Crossref]

13. Sharma S, Sundararajan A, Suryawanshi A, Kumar N, Veiga-Parga T, et al. (2011) $\mathrm{T}$ cell immunoglobulin and mucin protein-3 (Tim-3)/Galectin-9 interaction regulates influenza A virus-specific humoral and CD8 T-cell responses. Proc Natl Acad Sci U S A 108: 19001-19006. [Crossref]

14. Lu X, McCoy KS, Xu J, Hu W, Chen H, et al. (2015) Galectin-9 ameliorates respiratory syncytial virus-induced pulmonary immunopathology through regulating the balance between Th17 and regulatory T cells. Virus Res 195: 162-171. [Crossref]

15. Nebbia G, Peppa D, Schurich A, Khanna P, Singh HD, et al. (2012) Upregulation of the Tim-3/galectin-9 pathway of $\mathrm{T}$ cell exhaustion in chronic hepatitis $\mathrm{B}$ virus infection. PLoS One 7: e47648. [Crossref]

16. Katoh S, Ikeda M, Shimizu H, Mouri K, Obase Y, et al. (2014) Increased levels of plasma galectin-9 in patients with influenza virus infection. Tohoku J Exp Med 232: 263-267. [Crossref]

17. Liu KT, Liu YH, Chen YH, Lin CY, Huang CH, et al. (2016) Serum Galectin-9 and Galectin-3-Binding Protein in Acute Dengue Virus Infection. Int J Mol Sci 17. [Crossref]

18. Tandon R, Chew GM, Byron MM, Borrow P, Niki T, et al. (2014) Galectin-9 is rapidly released during acute HIV-1 infection and remains sustained at high levels despite viral suppression even in elite controllers. AIDS Res Hum Retroviruses 30: 6546-64. [Crossref]

Copyright: (C2019 Wen-Hung W. This is an open-access article distributed under the terms of the Creative Commons Attribution License, which permits unrestricted use, distribution, and reproduction in any medium, provided the original author and source are credited. 